\title{
The Application of Active Filters Supported by Pulse Width Modulated Inverters in the Harmonic Simulation of the High Power Electric Traction
}

\author{
P. Kiss ${ }^{1}$, A. Balogh ${ }^{2}$, A. Dán ${ }^{1}$ I. Varjasi ${ }^{2}$ \\ ${ }^{1}$ Department of Electric Power Engineering, Power Systems and Environment Group \\ Budapest University of Technology and Economics \\ Egry József u. $18,2^{\text {nd }}$ floor, H-1111 Budapest (Hungary) \\ Phone number: +0036 1 4633019, fax: +0036 1 4633013, e-mail: kiss2.peter@,vet.bme.hu, \\ dan.andras@vet.bme.hu. \\ ${ }^{2}$ Department of Automation and Applied Informatics \\ Budapest University of Technology and Economics \\ Goldmann György square 3, $4^{\text {th }}$ floor, H-1111 Budapest (Hungary) \\ Phone number: +0036 1 4631552, fax: +00361 4632871, e-mail: balogh@aut.bme.hu, varjasi@aut.bme.hu.
}

\begin{abstract}
The paper shows the present results of a long term research work. The authors are working on the modelling of active filtering of harmonics caused by the railways.

To simulate the harmonic penetration and filtering effects of the power electric traction the combination of frequency and time dependent model should be used. This novel method, called double domain simulation is improving the accuracy of the frequency domain simulation. To calculate the sophisticated model of the electric locomotive and active harmonic filter as a non-linear load a time dependent model must be used. The traction supply system together with the equivalent supply network impedance could be calculated in frequency domain. An iteration algorithm is developed converting the variables in every iteration step between the time and frequency domain.
\end{abstract}

\section{Keywords}

Power quality, traction supply systems, computer simulation, active harmonic filtering, PWM inverter

\section{Introduction}

Strict requirements were established on the voltage quality of the electric supply network in the last decade. One of these requirements is in connection with the harmonic distortion of the voltage. [2] The voltage distortion is caused by the non-linear loads connected to the network on different voltage levels. This distortion could cause faults both in the high power energy system and the parallel telephone lines.

After the spreading of locomotives supported by DC engines and rectifier units the disturbance originating from railway traction systems has increased. Harmonic filters are used to limit the harmonic currents flowing into the upstream network and to decrease the resonance effect causing current amplification along the $25 \mathrm{kV}$ supply line. Reducing the harmonic currents decreases the psophometric current and voltage.

In our paper the application of active filters are discussed for the Hungarian $25 \mathrm{kV}$ AC traction supply network. In the chapters of the paper the brief summary of the double domain simulation is presented, the detailed introduction of the active filtering, the ideal and the filter with PWM inverter are reported. Finally some calculation results (harmonic currents, and voltages, calculated psophometric values) have been published.

\section{Modelling the electric traction's supply}

The electric railway system is consisting of four main components (Fig. 1.a): [1]

- the locomotives

- the contact line system

- the feeding transformer

- the high voltage supply network

The locomotives are running under the contact line system, dividing it into two parts. At the contact point the locos could be represented by a fundamental frequency consumer and a harmonic current generator.

The contact line system should be considered as a multiconductor system with earth return that is composed of the contact wire(s), suspension wire(s), and the return rails. It can be reduced to a two-wire-system that leads the current. The feeding transformer could also be considered as a quadripole which consists of the magnetizing and the leakage reactance. The driving point impedance used for the system identification. 

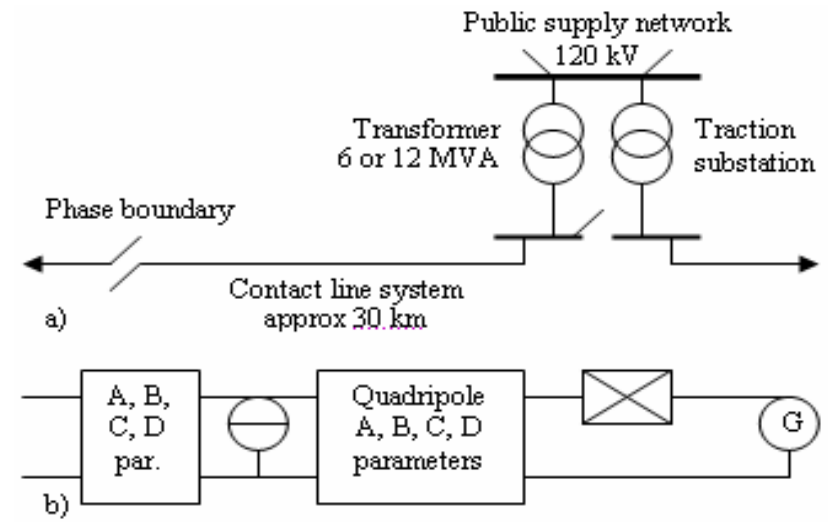

Fig. 1. Simplified circuit for calculation of harmonic effect

a) general traction-current feeding arrangement

b) circuit representation of contact line system

The parameters of the contact line system and transformer and the driving point impedance could be determined by laboratory and site measurements.

The traction supply system model can be made with these elements as it is shown in Fig. 1.b. This model is calculated in the frequency domain, because all the necessary parameters are given in the frequency domain. The computer simulation model of traction system is given on Fig. 2. [3]

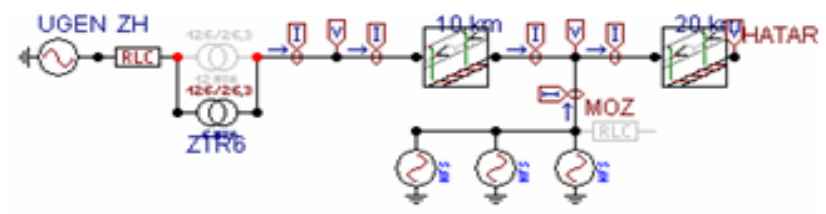

Fig. 2. The traction supply system model

For studying low frequency disturbance, the harmonic orders must be examined till the 50th harmonic. [2]

The locomotive model's block diagram and computer model could be seen on Fig. 3. To calculate the sophisticated model of the electric locomotive as a nonlinear load a time dependent model must be used. It determines the current spectrum of the engine in function of the distorted supply voltage. Because the voltage distortion is caused by the loco itself, an iteration algorithm was developed to convert the variables between the time and frequency domain vice and verse. [4]

\section{Harmonic effect}

The current harmonic components could cause the following problems:

- resonance effect with overvoltage and overcurrent consequences,

- additional losses,

- psophomentic disturbance of the telecommunication systems,

- disturbance in the remote control systems,

- malfunction of protection devices,

- misoperation of semiconductor-controllers.

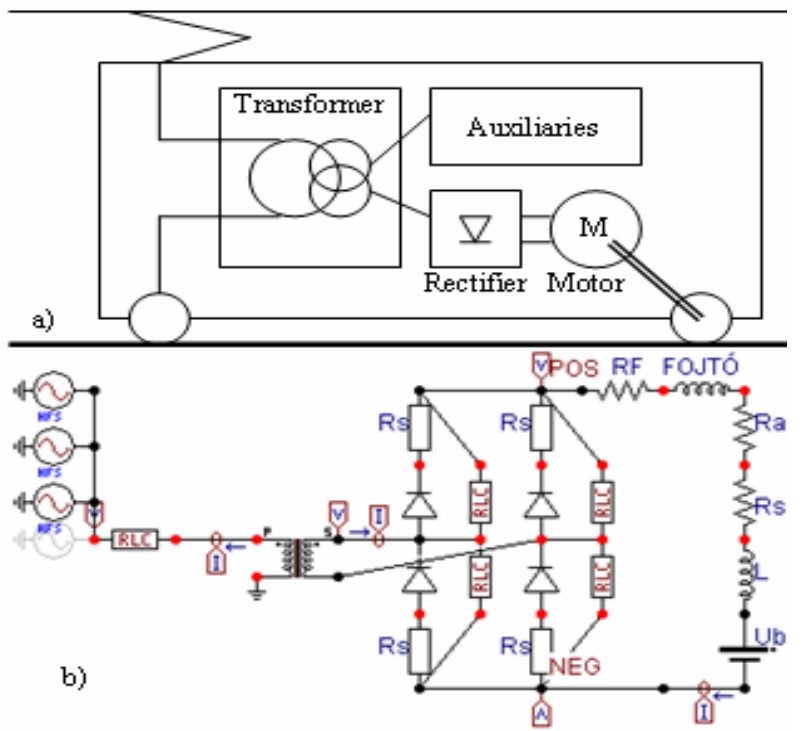

Fig. 3. Simplified locomotive model

a) block diagram, b) circuit representation

The harmonic disturbance basically could be characterized by the individual (1) and total (2) harmonic distortion factors:

$$
\begin{aligned}
D_{k} & =\frac{X_{k}}{X_{1}} \\
T H D_{X} & =\frac{\sqrt{\sum_{k=2}^{\infty} X_{k}^{2}}}{X_{1}}
\end{aligned}
$$

where

$k=\frac{f}{50 \mathrm{~Hz}}:$ the harmonic order,

$X_{k}$ : kth harmonic component of $I$ or $V$

$X_{1}$ : fundamental frequency component of $I$ or $V$.

\section{Psophometric interference}

The high power lines could influence the neighbouring telecommunication networks by the following ways:

- Capacitive coupling: The voltage of the power line causes charging current

- Inductive coupling: The line current induces longitudinal emf.

The most dominant part of the psophometric noise is the inducing effect caused by the zero sequence components of the current. The power balance of the three-phase is near symmetrical during normal operation, thus the coupling is measurable only if the distance between the two systems is comparable with the phase distance of one system. However electric traction is a single-phase system with ground return and in consequence it is a natural zero sequence system. That is why it is important to calculate the psophometric noise. [1] 
By telecommunication lines the rate of the disturbance could be characterized by the so called psophometric voltage. It could be calculated by this formula:

$$
V_{p}=\sqrt{\sum_{f}\left(\frac{p_{f}}{p_{800}} \cdot V_{f}\right)^{2}}
$$

where

$V_{f}$ : voltage component by $f$ frequency,

$p_{f}$ : psophometric weight by $f$ frequency,

$p_{800}=1000$.

The psophometric weight has been determined after human tests; it could be seen on Fig. 4. It could be concluded that the main part of the noise disturbance is caused by the $800 \mathrm{~Hz}$ and surrounding harmonics. The psophometric weighting could be applied for the current components, too, the formula is the same like in Eq. (3), however, this value is characteristic to the zero sequence current of power line regarding its possible disturbing effect. This is the so called disturbing current. [1]

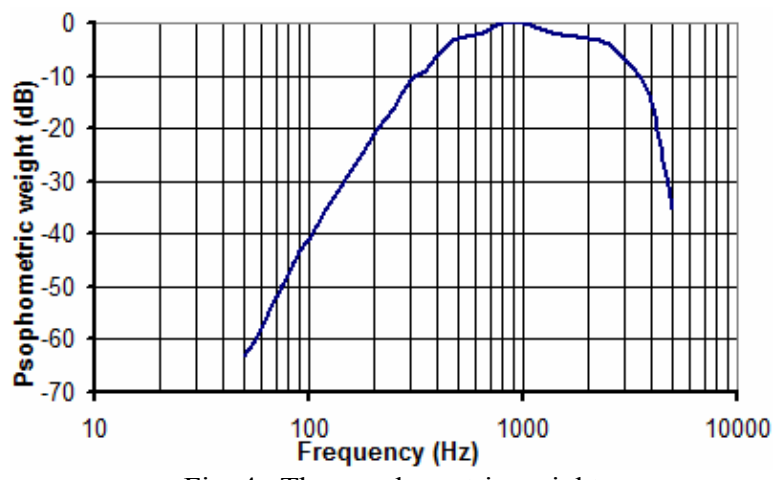

Fig. 4. The psophometric weight

\section{Harmonic filtering}

Harmonic filters are used to limit the harmonic currents flowing into the upstream network and to decrease the resonance effect causing current amplification along the $25 \mathrm{kV}$ supply line. The filter could be located on the loco itself or on the substation. Because of the different type of locos running simultaneously on the same traction section the most effective place for the harmonic filter location is the $25 \mathrm{kV}$ side of the substation. Basically there are two kinds of filters: passive and active filters.

\section{A. Passive filtering}

The passive harmonic filter is a set of series resonance circuits tuned to the frequencies to be filtered and connected parallel with the non-linear load to be filtered.. The passive harmonic filter has low impedance on its tuned frequency that is why it shunts the network for the harmonic current of the tuned harmonic order. Harmonic filtering is often linked with the problem of fundamental frequency reactive power balance. The passive filter is used to compensate inductive reactive power as well, because it shows capacitive reactance on the fundamental frequency. [1]

\section{B. Active filtering}

The active harmonic filtering is an electronic method to convert the basically non-sinusoidal current of the consumer into sinusoidal one regarding the resultant supply side network current. The active filters are controlled current generators controlled by microprocessors or microcontrollers, injecting the reciprocal value of selected frequency components or the whole distortion to the network. [3] [5]

\section{Applied active filter}

Nowadays the spreading of power semiconductors, system technologies and control strategies made possible the wide-ranging utilization of power converters. The voltage source converters even at high power have switching frequency high enough to be able to inject harmonic currents into the grid system. In this form they can be used for harmonic compensation. Depending on the power level, the application and the switching frequency there are several types of useable power converters. For harmonic compensation in case of railway applications the best choice is the single phase bridge inverter with alternative PWM controlled current control [6]. The main circuit arrangement of the inverter and the supply system model can be seen on Fig. 5 .

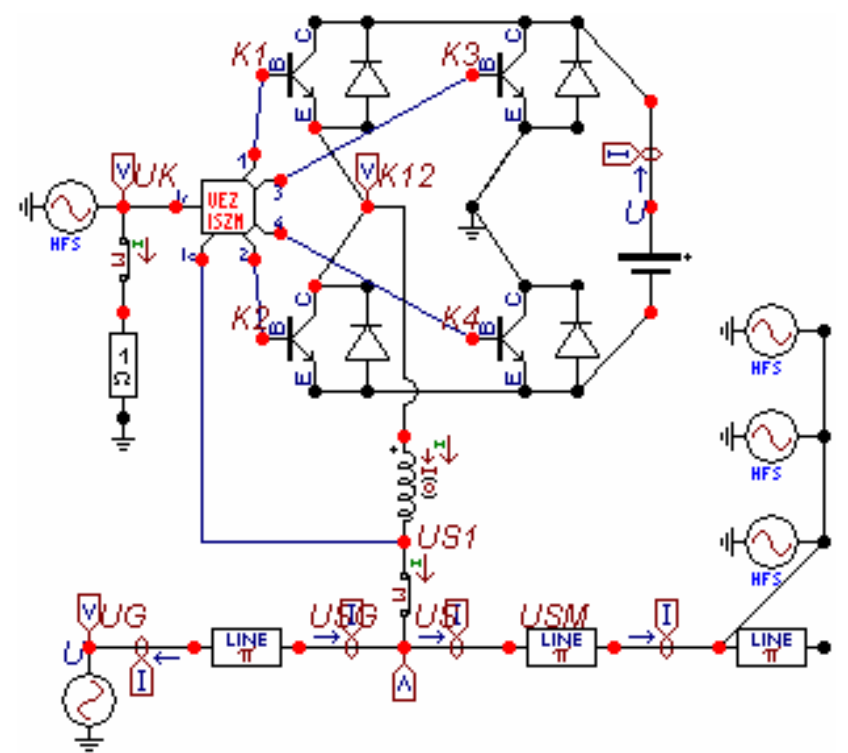

Fig. 5. The main circuit arrangement of the inverter

In our simulation some simplifications and conditions were applied as follows:

- The power semiconductors including power switches and freewheeling diodes are represented with ideal switches

- The control deadline between the upper and lower semiconductor in each leg, the switching- 
on and switching-off times of the semiconductors were neglected

- The serial R-C snubber circuits parallel with the switches are used to smooth the computed curves. These components not absolutely needed at the real circuit

- Alternative PWM is used for the less current ripple.

\section{A. The current control loop}

In theoretical view the controlled part is a serial R-L circuit, which can be easily controlled by a simple PI controller. The block diagram of the proposed control method is given on Fig. 6 .

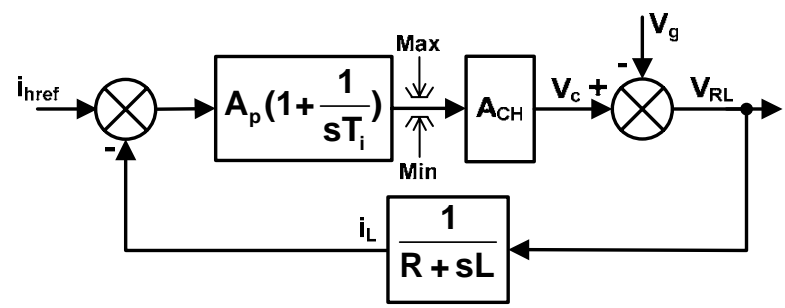

Fig. 6. The current control loop

where

$i_{\text {href: }}$ reference harmonic current,

$V_{c}$ : converter voltage, limited to the DC link voltage,

$V_{\mathrm{g}}$ : grid voltage,

$V_{R L}$ : voltage of the coupling inductor between the converter and the grid,

$I_{L}$ : injected harmonic current,

$R, L$ : resistance and inductance of the inductor,

$A_{P}, T_{i}$ : proportional gain and integration time of the PI controller,

$A_{C H}$ : constant of the inverter.

The main goal of this active filter was to eliminate above all the $3^{\text {rd }}$ and $5^{\text {th }}$ harmonic as the highest value harmonics of the traction supply system current (the calculation results could be studied in Chapter 7.A). Because the high power level and the maximal harmonic frequency $(250 \mathrm{~Hz})$ the optimal switching frequency was determined in $10 \mathrm{kHz}$. The maximal harmonic frequency is much less than the switching frequency, so the inverter can be replaced in the control loop as a proportional gain and the whole system can be handled as continuous system. The right setting method of the PI controller is given in the next subchapter.

\section{B. Setting of the current controller}

In the case of continuous system without delays the poles dropping method can be used to the setting.

The transfer function (see Fig. 6) of the open loop is:

$$
\frac{i_{L}(s)}{i_{\text {href }}(s)}=A_{p}\left(1+\frac{1}{s T_{i}}\right) A_{C H} \frac{1}{R+s L}
$$

Converting (4), the transfer function is the following:

$$
\frac{i_{L}(s)}{i_{\text {href }}(s)}=A_{p} A_{C H} \frac{1}{R} \frac{1+s T_{i}}{s T_{i}} \frac{1}{1+s T_{\text {ind }}}
$$

where $T_{\text {ind }}=L / R$ is the electrical time-constant of the inductor.

It is seen from (5), if the electrical time-constant is equal to the integration time of the PI controller than (5) will reduce as follows:

$$
\frac{i_{L}(s)}{i_{\text {href }}(s)}=A_{p} A_{C H} \frac{1}{R} \frac{1}{s T_{i}}=\frac{1}{s T_{\text {cont }}}
$$

where

$$
T_{\text {cont }}=\frac{R T_{i}}{A_{p} A_{C H}}
$$

From (6) the transfer function of the closed loop is:

$$
Y_{\text {cloop }}=\frac{1}{1+s T_{\text {cont }}}
$$

It can be seen that with this method the original control loop reduced to a simple one degree system. The timeconstant of the whole controlled system $\left(T_{\text {cont }}\right)$ was set to $10 \mu \mathrm{s}$, from (5) $T_{i}$ was set to $1 \mathrm{~ms}$ and finally the proportional gain from (7) was set to 3 . The proper operation of the active filter is verified with simulations (see chapter 7.).

\section{Calculation results}

Some characteristic simulation regarding the harmonic distortion of the railway systems in function of the locomotive position and locomotive type are discussed in the former papers [3] and [4]. Some special calculations are presented here by different filtering strategies using the traction system model (Fig. 2) with total length of 30 $\mathrm{km}$, and the locomotive model (Fig. 3.b) of this paper, where the locomotive is located $10 \mathrm{~km}$ far from the substation.

\section{A. Without filtering}

Some resonant effect can be studied along the supply line. This is a parallel resonance which is caused mainly by the inductance of the transformer and the distributed capacitance of the contact line system. [1] [3] Using the model it is possible to calculate the voltage and current spectrum along the supply line. As an example on Fig. 7, 


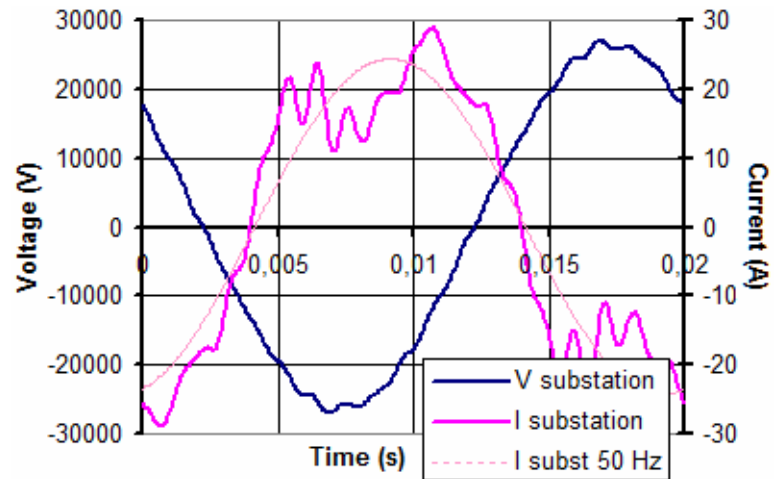

Fig. 7. Substation $\mathrm{V}$ and I without filtering

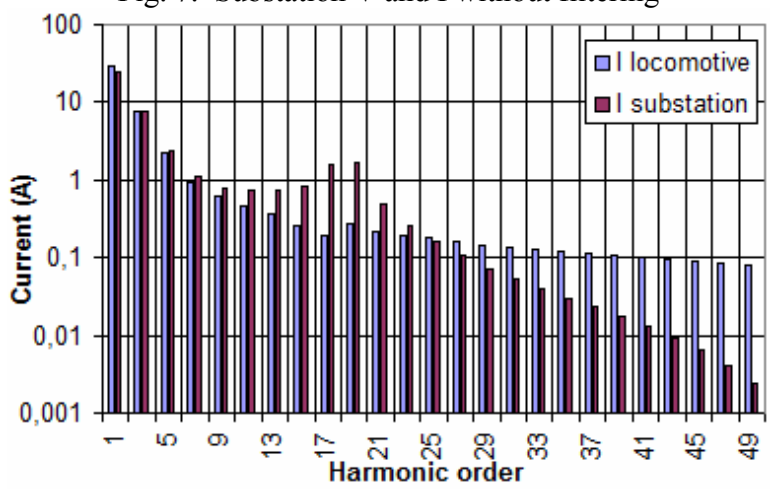

Fig. 8. Spectrum of currents (loco and substation)

the voltage and current at the substation are seen. On Fig. 8 the calculated substation and locomotive current spectrum can be studied. The current spectrum of the locomotive is very characteristic for the AC side of DC motors supported by AC/DC converters. [4] Comparing with the substation spectrum, it could be concluded, that the resonance effect is the highest at the $17^{\text {th }}$ and $19^{\text {th }}$ harmonics. Over the $25^{\text {th }}$ harmonic the supply system is decreasing the harmonic current, like a harmonic filter.

The highest values of currents could be measured on the $3^{\text {rd }}$ and $5^{\text {th }}$ harmonics, the values of these components are near the same by the locomotive and the substation. It is possible to apply the active filter of Chapter 6 to reduce these harmonics.

\section{B. Using the active filter of Chapter 6}

After installing an active filter in the substation the following results can be calculated. (Fig. 9) This filter is a PWM controlled current generator injecting the calculated $3^{\text {rd }}$ and $5^{\text {th }}$ harmonic current as anti-phase

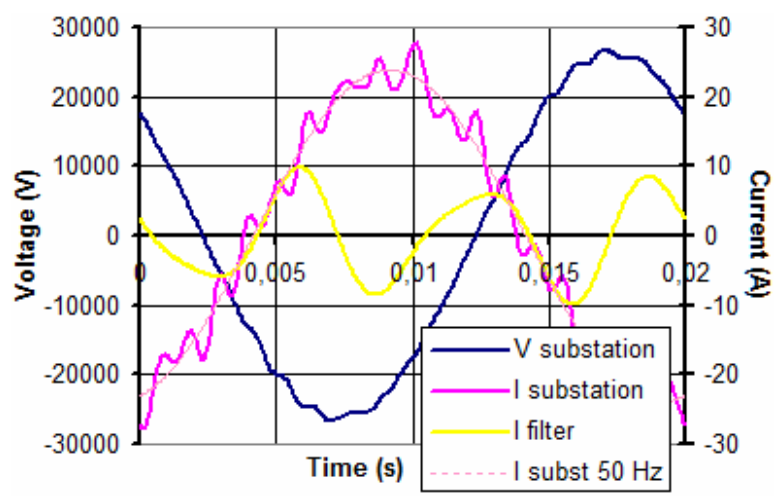

Fig. 9. Substation $\mathrm{V}$ and I with filtering value at the substation.

It could be concluded that the current and voltage component on the filtered harmonic orders are reduced dramatically and the typical effect of the $3^{\text {rd }}$ and $5^{\text {th }}$ harmonics have been neglected, but the significant high frequency components (mainly $17^{\text {th }}$ and $19^{\text {th }}$ harmonics) have remained. Because of the limitations of the switching frequency, the PWM active filters could not be applied effectively for such high frequencies. To filter this effect, a passive filter - for example a broadband one - should be used.

\section{Psophometric and THD values}

Using the harmonic components of the currents and voltages the psophometric and THD values can be calculated along the supply line. The Table I shows the value of the psophometric voltages by the substation and psophometric currents by the substation on the contact line and the upstream network side unfiltered one. Besides this the THD values are given in the table.

TABLE I. - Psophometric and THD Values

\begin{tabular}{|l|c|c|c|}
\cline { 3 - 4 } \multicolumn{2}{c|}{} & UNFILTERED & FILTERED \\
\hline \multirow{2}{*}{ V substation } & $\mathrm{V}_{\mathrm{p}}$ & $465.65 \mathrm{~V}$ & $477.04 \mathrm{~V}$ \\
\cline { 2 - 4 } & $\mathrm{THD}_{\mathrm{V}}$ & $2.11 \%$ & $1.88 \%$ \\
\hline \multirow{2}{*}{ I HV>subst } & $\mathrm{I}_{\mathrm{p}}$ & $2.76 \mathrm{~A}$ & $2.81 \mathrm{~A}$ \\
\cline { 2 - 4 } & $\mathrm{THD}_{\mathrm{I}}$ & $35.46 \%$ & $13.28 \%$ \\
\hline \multirow{2}{*}{ I subst>loco } & $\mathrm{I}_{\mathrm{p}}$ & $2.76 \mathrm{~A}$ & $2.84 \mathrm{~A}$ \\
\cline { 2 - 4 } & $\mathrm{THD}_{\mathrm{I}}$ & $35.46 \%$ & $35.61 \%$ \\
\hline
\end{tabular}

\section{Conclusion}

It can be concluded that using active harmonic filtering the network side harmonic distortion is reduced very effectively, but the psophometric effect caused by the current along the traction system basically did not change. Quite the contrary, a minimal increase could be seen. In critical cases a broadband passive filter might be necessary to decrease the harmonic impedance resonance causing the increase of equivalent disturbing current.

This kind of calculation is a suitable method to perform an analysis on both the harmonic distortion and psophometric effect. The double domain simulation method will help to select the most advantageous solution, regarding the composition of passive and active harmonic filtering. [3]

\section{Future plans}

In our model the DC link voltage is made by an outer $\mathrm{AC} / \mathrm{DC}$ converter. This solution is very expensive, because an auxiliary power converter is needed. However, there is a better solution too. With using of capacitors in the DC link the converter's cost decrease, but the converter control will be much more complicated. In case of capacitors two control loops is needed, one outer loop for the DC link voltage control and one inner loop for the harmonic current injection. The capacitors 
are charged with base harmonic currents through the freewheeling diodes and the capacitor is charged out through the switches with harmonic currents. The block diagram of the modified control can be seen in Fig. 10.

The harmonic injection efficiency can be increased with adaptive current control and PLL based synchronization to the harmonics.

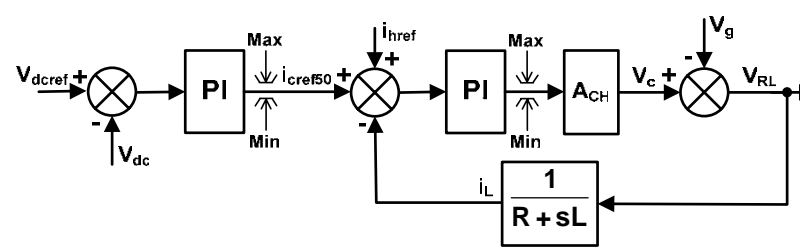

Fig. 10. Control structure in case of capacitors in the DC link

where

$i_{\text {href50: }}$ base harmonic capacitor charging current reference,

$V_{\text {dcref: }}$ DC link voltage reference,

$V_{d c}:$ DC link voltage.

In our previous work [7] [8] we successfully developed a new control strategy for single and three phase converters, with which the converter efficiency can be improved. The so called 3SC (three state current control) method was successfully tested on $10 \mathrm{~kW}$ converters with about $1 \%$ efficiency increase. The using of 3SC method without any hardware changes in the main circuit may increase the converter efficiency. This control has reactive power and harmonic compensation capability up to the $25^{\text {th }}$ harmonic with high converter efficiency.

\section{Acknowledgement}

The importance of this paper indicates that its topic is fit to one of the projects of the Hungarian State Railways.
This is the project of planning active harmonic filters to the railways' substations to reduce the harmonic distortion, resulting in reduction of losses, and better voltage quality.

\section{References}

[1]. A. Dán, J. Kisvölcsey, Gy. Varjú: Filtering of harmonics generated by thyristor controlled AC traction systems. In Proc. II. International Conference on Harmonics in Power Systems, pp.404-413., Winnipeg, 6-7. October, 1986.

[2]. A. Dán, T. Tersztyánszky, Gy. Varjú: Electric Power Quality (Villamosenergia minőség). Budapest: InvestMarketing Ltd, 2006.

[3]. A. Dán, P. Kiss: Effect on Power Quality of the High Power Electric Traction (Double Domain Computer Simulation vs. Site Measurements). In Proc. International Conference on Renewable Energies and Power Quality, Palma de Mallorca, 5-7. April 2006.

[4]. A. M. Dán, P. Kiss: Advanced Calculation Method for Modeling of Harmonic Effect of AC High Power Electric Traction. In Proc. 12th International Conference on Harmonics and Quality of Power, Cascais, 1-5. October 2006.

[5]. P. Brogan, R. Yacamini: Measurements and simulation of an active filter based on voltage feedback. In Proc. 8th. International Conference on Harmonics and Quality of Power pp.930-939., Athens, 14-16. October, 1998.

[6]. M. Revisnyei, I. Varjasi, A. Kárpáti, I. Hermann: Investigation of Harmonic Currents of Single Phase Bridge Converter with digital PWM, In Proc. PEMC 98, pp.6.89 - 6.93., Prague, 8-10. September, 1998.

[7]. A. Balogh, I. Varjasi: Discontinuous Current Mode of a Grid Connected PV Converter. In Proc. International Youth Conference on Energetics, Budapest, 31. May-2. June, 2007.

[8]. A. Balogh, Z. T. Bilau, I. Varjasi: High Efficiency Control of a Grid Connected PV Converter, In Proc. Power and Energy Systems Conference, Palma de Mallorca, 29-31. August, 2007. 